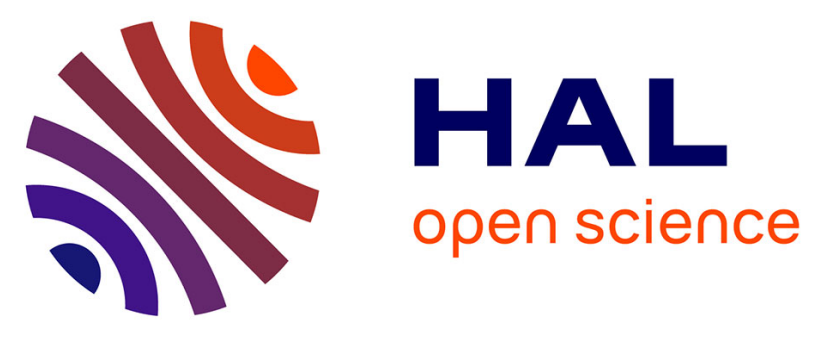

\title{
Bare laser-synthesized palladium-gold alloy nanoparticles as efficient electrocatalysts of glucose oxidation for energy conversion applications
}

Yaovi Holade, Seydou Hebié, Ksenia Maximova, Marc Sentis, Philippe

Delaporte, Kouakou Boniface Kokoh, Teko Napporn, Andrei Kabashin

\section{To cite this version:}

Yaovi Holade, Seydou Hebié, Ksenia Maximova, Marc Sentis, Philippe Delaporte, et al.. Bare laser-synthesized palladium-gold alloy nanoparticles as efficient electrocatalysts of glucose oxidation for energy conversion applications. Catalysis science and Technology, 2020, 10 (23), pp.7955-7964. 10.1039/d0cy01323d . hal-03160684

\section{HAL Id: hal-03160684 https://hal.science/hal-03160684}

Submitted on 10 Mar 2021

HAL is a multi-disciplinary open access archive for the deposit and dissemination of scientific research documents, whether they are published or not. The documents may come from teaching and research institutions in France or abroad, or from public or private research centers.
L'archive ouverte pluridisciplinaire HAL, est destinée au dépôt et à la diffusion de documents scientifiques de niveau recherche, publiés ou non, émanant des établissements d'enseignement et de recherche français ou étrangers, des laboratoires publics ou privés. 
Received 00th January 20xx, Accepted 00th January 20xx DOI: $10.1039 / \times 0 \times x 00000 x$

\title{
Bare laser-synthesized palladium-gold alloy nanoparticles as efficient electrocatalysts of glucose oxidation for energy conversion applications
}

\author{
Yaovi Holade, ${ }^{\mathrm{a}, \mathrm{b}}$ Seydou Hebié, ${ }^{\mathrm{a}, \mathrm{c}}$ Ksenia Maximova, ${ }^{\mathrm{d}}$ Marc Sentis, ${ }^{\text {,e }}$ Philippe Delaporte, ${ }^{\text {d,e }}$ Kouakou \\ Boniface Kokoh, ${ }^{\text {a }}$ Teko W. Napporn, ${ }^{* a}$ Andrei V. Kabashin*d,e
}

\begin{abstract}
Electrochemical energy converters based on biomass-based organic molecules such as glucose have recently demonstrated a great potential for the development of functional bioimplantable devices such as pacemakers, but such converters are lacking of efficient metal-based anode nanocatalysts, which could combine stability of parameters with high performance. Here, we elaborate methods of femtosecond laser ablation in water to synthesize bare (ligand-free) PdAu alloy nanoparticles with a variable ratio of its constituents and explore them as electrocatalysts of glucose oxidation. Our data evidence that the combination of two metals in one bare nanoformulation can result in a strong synergetic effect, which renders possible the combination of high catalytic activity toward glucose oxidation with ultrafast kinetic at low potentials due to the presence of $\mathrm{Au}$ and $\mathrm{Pd}$, respectively, while bare uncontaminated surface ensures outstanding catalytic performance. We show that under optimal ratio of constituents $(50 \% / 50 \%)$, PdAu nanoparticles can provide the mass activity of $60 \mathrm{~A} \mathrm{mg}^{-1}$ and the onset potential lower than $0.27 \mathrm{~V}$ vs. RHE, which outperforms all currently existing nanoparticle-based electrodes. Our results show that bare nanomaterials prepared by laser-ablative synthesis can offer much improved characteristics as electrocatalysts for energy conversion and storage applications, while the versatility of laser synthesis can be extended to other alloy architectures in order to provide optimal characteristics for a concrete catalytic task
\end{abstract}

\section{Introduction}

Capable of converting chemical energy of abundant bio-organic molecules (typically glucose or other sugars) into electrical output via electrochemical reactions, biofuel cells have recently appeared as novel promising systems, which can work under physiological conditions and thus offer novel applications, including micro scale output power sources for medical implants such as pacemakers. ${ }^{1,2}$ Direct glucose fuel cells take advantage of glucose oxidation process, which leads to the generation of sustainable energy, accompanied by the production of added-value reaction products such as gluconic, glucuronic and glucaric acids. ${ }^{3,4}$ Conventional biofuel cells use enzymes as electrocatalysts to initiate both the oxidation of glucose (anode) and the reduction of oxygen (cathode), but

\footnotetext{
a. Université de Poitiers, IC2MP UMR 7285 CNRS, 4, rue Michel Brunet B27, TSA 51106, 86073 Poitiers Cedex 9, France

b. Present address: Institut Européen des Membranes, IEM UMR 5635, Univ Montpellier, ENSCM, CNRS, 300 Ave. du Prof. Emile Jeanbrau, 34090 Montpellier, Cedex 5, France

c. Present address: Pilote Innovation, 212 Bd Pelletier, 78955 Carrières Sous-Poissy.

d. Aix Marseille University, CNRS, LP3 UMR 7341, Campus de Luminy, Case 917,

13288, Marseille cedex 9, France

e. MEPhl, Institute of Engineering Physics for Biomedicine (PhysBio), 115409 Moscow, Russia

*T. W. Napporn: teko.napporn@univ-poitiers.fr

*A. V. Kabashin : kabashin@lp3.univ-mrs.fr

Electronic Supplementary Information (ESI) available: [details of any supplementary information available should be included here]. See DOI: 10.1039/x0xx00000x
}

such cells require a permanent supply of dioxygen to regenerate cathode catalyst, which typically leads to a rapid (within a few weeks) degradation of cell performance. ${ }^{5}$ The improvement of stability and catalytic characteristics of biofuel cells can be achieved by the employment of hybrid schemes, in which metallic nanoparticles (NPs) are used as electrocatalysts. ${ }^{6}$ As shown in Fig. 1, the operation of such schemes consists of two phases: (i) Dehydration step, which consists in glucose adsorption through the $\beta$-hydrogen atom of $\mathrm{C} 1$-position that has better spatial arrangement. This step makes possible ultrafast kinetics at lower potentials and a sharp start of reaction with minimum overpotential; (ii) Glucose oxidation step, which implies the formation of adsorbed gluconolactone

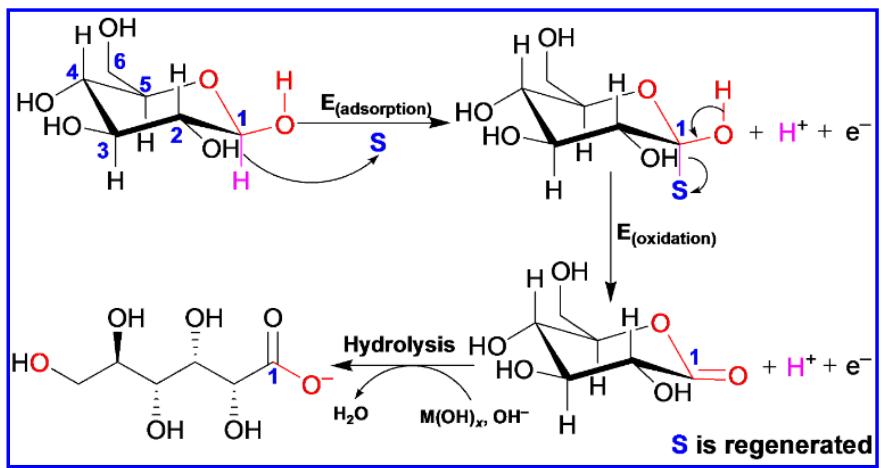

Fig. 1 General scheme for glucose electrooxidation at metallic electrodes. $S$ denotes the catalytic active site of the metal $\mathrm{M}$ where the reaction takes place; $\mathrm{M}(\mathrm{OH})_{\mathrm{x}}$ is the hydroxyl species involved in the reaction 
that will further undergo a hydrolysis into gluconate. This compound is the main product detected from the glucose oxidation, as shown in recent investigations. ${ }^{4}, 7$ Here, the electrode should have a strong poisoning resistance during the whole procedure in order to withstand the deactivation phenomena during subsequent cycles.

Owing to particular physico-chemical properties, gold nanostructures are considered among best candidates to enable the glucose oxidation step and their efficiency was confirmed in a variety of geometries. ${ }^{4,8}, 9$ Gold is also known by its exceptional chemical stability, which helps to achieve a high poisoning resistance of Au-based electrodes compared to most alternative materials. In addition, gold nanomaterials used as core promote enhanced electronic effect on the electrochemical activity of nanocrystals shell of transition metals. ${ }^{10,11}$ One of major challenges in designing Au NPs-based electrodes consists in the difficulty of purification of nanoparticle surface as Au NPs prepared by conventional chemical routes are typically coated by protecting ligands and surfactants. ${ }^{12-14}$ As the catalytic activity of metal NPs mainly originates from high-energy surface states, the presence of such ligands and surfactants inevitably decreases the efficiency of glucose oxidation process. ${ }^{9}, 15$ As a solution of this surface conditioning problem, we recently proposed to employ newlyemerging bare (ligand-free) NPs synthesized by methods of femtosecond laser ablation in deionized water. ${ }^{16-20}$ Due to particular conditions of laser synthesis, such NPs have exceptional purity and high colloidal stability even in the absence of protecting ligands. ${ }^{16,} 17$ Profiting from such an uncontaminated, ligand-free surface and particular physicochemical characteristics of laser-synthesized NPs, we demonstrated an order of magnitude better efficiency of such a nanomaterial in glucose electrooxidation compared to all $\mathrm{Au}$ counterparts prepared by conventional chemical synthesis routes. ${ }^{21}$ However, despite such impressive electrocatalytic activity during the glucose oxidation step, low affinity of gold with hydrogen complicates efficient dehydration step and does not render possible ultrafast kinetics for glucose adsorption at low potentials. ${ }^{22}$ We believe that dehydration properties of $\mathrm{Au}$ NPs-based electrode could be much improved by alloying gold with alternative metals, which exhibit better performance during the dehydration step. Here, palladium (Pd) looks as the most promising metal due to high natural affinity with hydrogen. ${ }^{23,} 24$ Chemically-synthesized PdAu alloys have been assessed in many studies and Mazzone et al. ${ }^{25}$ showed that the $\mathrm{Pd}-\mathrm{Au}$ bond was stronger than $\mathrm{Au}-\mathrm{Au}$ bond, while low coordinated $\mathrm{Pd}$ ensembles could be primarily responsible for the high activity in this alloy system. Profiting from a combination of advantages offered by $\mathrm{Au}$ and $\mathrm{Pd}, \mathrm{PdAu}$ nanoalloy structures have already been successfully used in a variety of catalytic applications. ${ }^{26-31}$ The exploration of bare (ligand-free) PdAu alloy NPs in glucose oxidation looks like a new attractive opportunity as such NPs could profit from dehydration property of $\mathrm{Pd}$ and oxidation property of $\mathrm{Au}$ in conditions of ligand-free surface.

Here, we employ methods of femtosecond laser ablation in deionized water to engineer ligand-free $\mathrm{PdAu}$ alloy nanoparticles with variable composition of its constituents and assess the efficiency of these nanoparticles as electrodes in glucose oxidation tasks. We show that the addition of Pd to nanoparticle composition indeed leads to a drastic improvement of catalytic performance by lowering the onset potential and much improving kinetic at low potentials, while bare, uncontaminated surface of alloy NPs makes possible the achievement of supreme characteristics compared to previously reported PdAu-based or other metal alloy counterparts.

\section{Results and discussion}

\subsection{Synthesis and characterization of bare PdAu nanoparticles}

For the synthesis of PdAu NPs we adapted methods of ultrashort laser ablation and fragmentation in liquid ambience, which were earlier used for the preparation of bare $\mathrm{Au}^{16-19}$ and $\mathrm{Si}^{32}, 33 \mathrm{NPs}$. Our approach for nanoalloy synthesis was based on the co-fragmentation of the mixture of two types of metallic nanoparticles. First, we fabricated separately $\mathrm{Au}$ and $\mathrm{Pd}$ nanoparticles. Radiation from a femtosecond laser (Yb:KGW, $1025 \mathrm{~nm}, 1-100 \mathrm{kHz}$ ) was focused onto $\mathrm{Au}$ and Pd targets placed on the bottom of a glass vessel filled with deionized water in order to initiate ablation of material. All conditions were identical $\mathrm{Au}$ and $\mathrm{Pd}$ targets, while the targets were continuously moved at a speed of $2 \mathrm{~mm} \mathrm{~s}^{-1}$ during the ablation step to avoid ablation from the same point. The resulted solution of Pd nanoparticles was grey and opaque, while the solutions of Au nanoparticles were deeply red. Transmission Electron Microscopy (TEM) studies showed that mean size of both $\mathrm{Au}$ and Pd NPs formed by fs laser ablation was about 25 $\mathrm{nm}$. Au and Pd metal colloids were then mixed at different molar ratios and irradiated with 1025-nm femtosecond laser pulses, at the $55 \mu \mathrm{J}$ of the pulse energy. As we showed in our previous papers, the focusing of fs radiation in water leads to the generation of white light supercontinuum, which presents a broad white light spectrum of the femtosecond length, which can cause the fragmentation of colloids. ${ }^{17}$ In our experiments, such supercontinuum led to ablation of both $\mathrm{Au}$ and $\mathrm{Pd}$ nanoparticles and subsequent formation of PdAu allows and this process took about 45 minutes to complete the alloy formation process. The colour of the mixture of two kinds of nanoparticles changed from reddish-grey to light brown, as is indicated on the inset of Fig. 2a. Figure 2a shows a temporal evolution of UV-Vis absorption spectra for the mixture of Au and $\mathrm{Pd}$ nanoparticles under their irradiation by a focused fs beam. As shown in the Figure, the absorption peak associated with a plasmonic absorption of gold NPs $(520 \mathrm{~nm})$ completely disappeared after 45 minutes of laser fragmentation. The evolution of colour and absorption spectra of the mixture of NPs was consistent with the formation of a PdAu alloy. As follows from Fig. 2b, the formed nanoparticles were spherical and welldispersed, while their mean size was $4-5 \mathrm{~nm}$. It is worth noting that the size of fragmented PdAu alloys was smaller than the original size of initial $\mathrm{Pd}$ and $\mathrm{Au}$ colloids, which was probably related to different mechanisms and conditions of ablation 



Fig. 2 (a) UV-Vis absorption spectra of the mixture of Au and Pd NPs before and after the irradiation. The inset shows a Photo of the mixture of Au and Pd NPs before (left) and after 45 min (right) of the irradiation; (b) TEM image and a corresponding size distribution of PdAu alloy NPs; Inset: High resolution TEM image of a typical AuPd alloy nanoparticle

from a solid target and fragmentation of colloids. A detailed investigation of structural properties of PdAu NPs revealed the interplanar spacing for adjacent crystal planes of $2.3 \AA$, which corresponds to (111) plane of face-centered cubic Au and Pd, as well as to (111) crystal plane of PdAu alloy. ${ }^{34}$ Polycrystalline structure of alloy nanoparticles is typical for the ultra-short pulse ablation/fragmentation. This structure arises from the coalescence of small fragments formed during the fission of the nanoparticles. Smaller clusters and isolated atoms participate in the smoothing of the nanoparticles.

As followed from our preliminary electrocatalytic tests, only PdAu NPs having more than $40 \%$ of Pd exhibited remarkably different activity toward glucose oxidation compared to pure $\mathrm{Au}$ NPs. Therefore, for our studies, we chose the following compositions of alloys: $\mathrm{Pd}_{50} \mathrm{Au}_{50}(50 \% / 50 \%)$ and $\mathrm{Pd}_{83} \mathrm{Au}_{17}$ (83\%/17\%). For comparison, we also employed "bare" lasersynthesized Au and Pd NPs.

\subsection{Electrochemical evidence of PdAu nanoalloys formation}

Typical voltammograms of $\mathrm{PdAu}$ catalysts having different ratios of $\mathrm{Pd}$ and $\mathrm{Au}$ in $0.1 \mathrm{M}$ are shown in Figure 3a. To avoid the electrochemical absorption of hydrogen in the Pd network, CV of Pd-based electrodes were recorded by fixing the lower potential at $0.3 \mathrm{~V}$ vs. RHE. ${ }^{35}$ Indeed, for electrode potentials lower this threshold, Pd starts to absorb hydrogen in aqueous media. However, the presence of another organic molecule such glucose might inhibit this process. We noticed that CVs recorded with a lower potential of $0.05 \mathrm{~V}$ vs. RHE are not stable in $0.1 \mathrm{M} \mathrm{NaOH}$ since the electrochemically absorption of hydrogen in the palladium crystal lattice is not fully reversible (Fig. S1). However, our later experiments showed that the presence of $10 \mathrm{mM}$ glucose enables to reach a steady-state
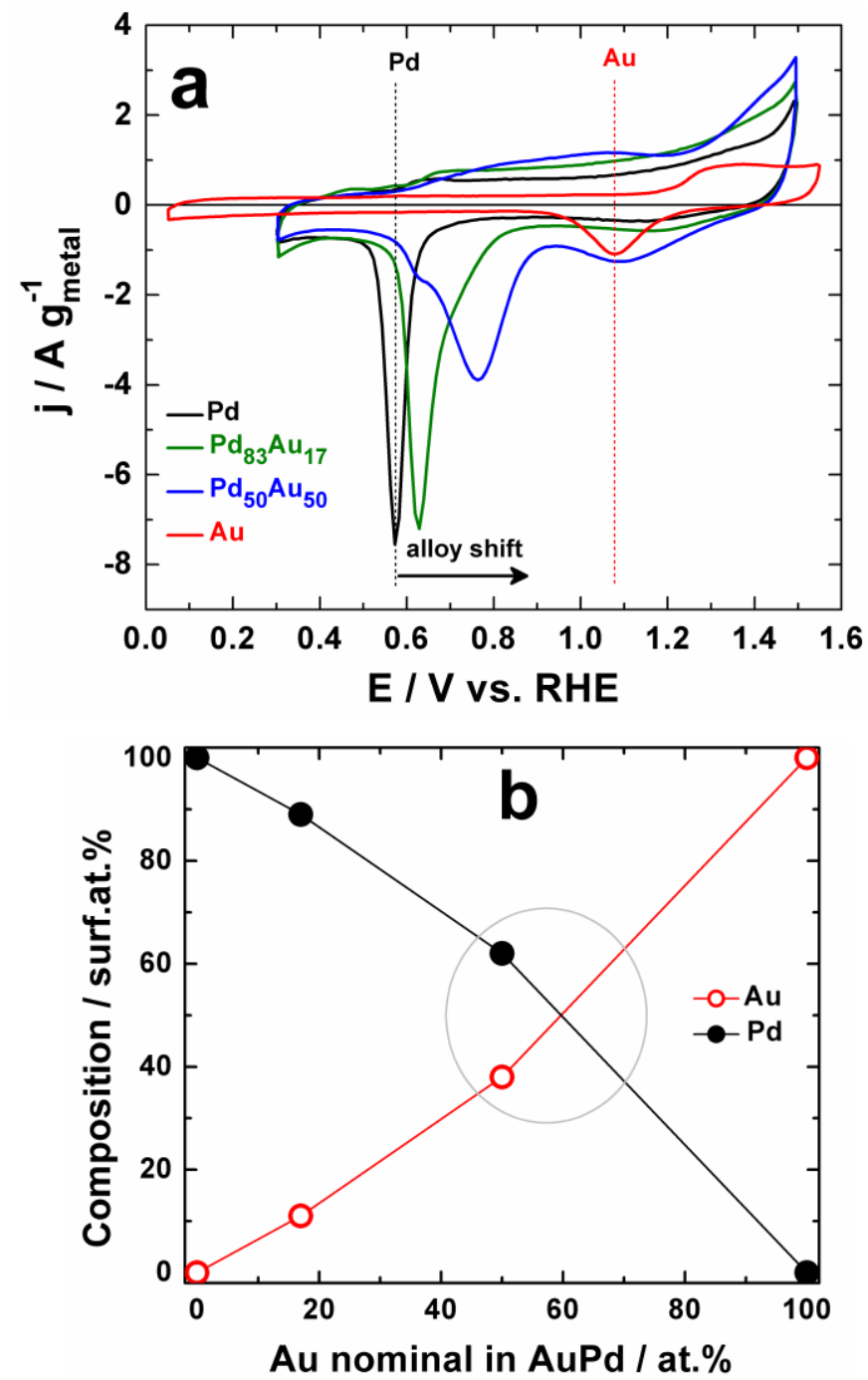

Fig. 3 (a) Steady-state CV curves of $\mathrm{Pd}_{\mathrm{x}} \mathrm{Au}_{\mathrm{y}}$ electrodes formed by laserablated NPs recorded in $0.1 \mathrm{M} \mathrm{NaOH}$ at $20 \mathrm{mV} \mathrm{s}^{-1}$ and at a controlled temperature of $20^{\circ} \mathrm{C}$. (b) Surface atomic composition determined from the Rand and Woods method (Eq. (1)), based on CVs of (a)

condition within few cycles, thus underpinning the conclusion that the adsorption of glucose hinders the hydrogen absorption process in Pd crystal lattice.

Fig. 3a illustrates a synergistic effect in Pd-Au bimetallic nanostructures. One can see that such structures exhibit one major peak where the oxide is reduced and this peak shifts towards higher potentials when gold content increases in the bimetallic material. On other hand, only one phase, that one of the alloy, is formed. Such observations were attributed by several authors to either a palladium-gold interaction in an alloy phase ${ }^{36-38}$ or nanoparticles size effect. ${ }^{39}$ The vertical dotted lines represent potentials of the reduction peaks of palladium oxide (PdO: $0.57 \mathrm{~V}$ vs. $\mathrm{RHE}$ ) and gold oxides ( $\mathrm{AuO}_{\mathrm{x}}$ : $1.08 \mathrm{~V}$ vs. $\mathrm{RHE}$ ). The oxide reduction peak during the negative potential scanning of $\mathrm{Pd}_{83} \mathrm{Au}_{17}$ is situated at $0.63 \mathrm{~V}$ vs. RHE. For $\mathrm{Pd}_{50} \mathrm{Au}_{50}$ the main reduction peaks at ca. $0.76 \mathrm{~V}$ vs. RHE is accompanied by a large shoulder at $1.1 \mathrm{~V}$ vs. RHE that could be assigned to an unalloyed $\mathrm{Au}$ in the material, as observed by Simões et al. ${ }^{37}$ The remarkable shift of the reduction peak of oxides $(\Delta E=200 \mathrm{mV}$ 
for $\mathrm{Pd}_{50} \mathrm{Au}_{50}$ compared to pure $\mathrm{Pd}$ ) probably results from $\mathrm{Au}$ surface oxidation, which takes place from ca. $1.2 \mathrm{~V}$ vs. RHE during the positive potential going-scan. This explanation is supported by the fact that at this potential, no oxygen evolution reaction occurs on the $\mathrm{Au}$ surface, even if the potential is increased up to $1.6 \mathrm{~V}$ vs. RHE. ${ }^{15}$ Another explanation can be related to palladium-gold electronic interactions in the alloy phase. ${ }^{37,40}$

To gain further insights on distinguished interaction between palladium and gold atoms in bimetallic materials, we used the electrochemical method proposed by Rand and Woods ${ }^{41}$ to estimate the surface atomic composition of the $\mathrm{PdAu}$ electrodes according to Eq. (1). Since electrocatalysis efficiency critically depends on surface condition, an elegant route to design advanced electrocatalysts with much enhanced activity, durability and lifespan consists in intelligent engineering of a proper surface structure. This further enables to maximize exposure of the most active sites to reactive species for improving the throughput of the reaction kinetics.

$$
\mathrm{E}_{\text {peak }}^{\text {PdAu }}=\chi_{\text {Pd }} E_{\text {peak }}^{\text {Pd }}+\chi_{\text {Au }} E_{\text {peak }}^{\text {Au }} \Rightarrow \chi_{\text {Pd }}=100\left(\frac{E_{\text {peak }}^{\text {PdAu }}-E_{\text {peak }}^{\text {Au }}}{E_{\text {peak }}^{\text {Pd }}-E_{\text {peak }}^{\text {Au }}}\right)
$$

$\chi_{\mathrm{Pd}}$ and $\chi_{\mathrm{Au}}\left(\chi_{\mathrm{Pd}}=100-\chi_{\mathrm{Au}}\right)$ are $\mathrm{Pd}$ and $\mathrm{Au}$ surface atomic percentages (surf.at.\%) and $E_{\text {peak }}^{P d}, E_{\text {peak }}^{A u}$ and $E_{\text {peak }}^{\text {PdAu }}$ are oxide reduction peak potentials for $\mathrm{Pd}, \mathrm{Au}$ and $\mathrm{PdAu}$, respectively.

Surface atomic compositions obtained from Eq. (1) are displayed in Fig. 3b. As shown in the Figure, $\mathrm{Pd}_{83} \mathrm{Au}_{17}$ electrode, composed of 89 surf.at.\% Pd and 17 surf.at.\% $\mathrm{Au}$, has a good match of the overall composition (83/17) and surface composition (89/11), which confirms a successful formation of a nano-alloy structure. For $\mathrm{Pd}_{50} \mathrm{Au}_{50}$ electrode material, $\chi_{\mathrm{Pd}}=62$ surf.at.\% Pd and $\chi_{A u}=38$ surf.at.\% Au. Even if the composition does not match the projected ideal ratio of 50/50, it shows slight surface enrichment by $\mathrm{Pd}$ atoms, which promises important advantages for electrocatalysis. Indeed, in fuel cells the electrode potential of the anode is expected not to exceed $0.7 \mathrm{~V}$ vs. RHE during the operation, which enables to reach a high cell voltage and subsequently obtain a high output power. At low electrode potentials such as those for $\mathrm{E}<0.4 \mathrm{~V}$ vs. $\mathrm{RHE}$, the electrocatalytic activity towards electrooxidation of organic molecules (and particularly carbohydrates) increases in the order of $\mathrm{Au}<\mathrm{Pd}<\mathrm{Pt}$. However, for the durability/stability, the order is reversed, i.e. $\mathrm{Au}>\mathrm{Pd}>\mathrm{Pt}$. Consequently, $\mathrm{Pd}_{50} \mathrm{Au}_{50}$ alloy is expected to show the most distinguishable electrocatalytic performance. Recently Holade et al ${ }^{35}$ reported the fabrication of a highly efficient nanocatalyst $\mathrm{Pd}_{10} \mathrm{Au}_{90} /$ Vulcan, whose surface composition is 62 surf.at.\% Pd and 38 surf.at.\% Au. XPS measurements showed that the synthesized $\mathrm{Pd}_{10} \mathrm{Au}_{90} /$ Vulcan nanomaterial demonstrates ca. $0.3 \mathrm{eV}$ downshift of the binding energy compared to $\mathrm{Pd} / \mathrm{C}$ for the core-level $\mathrm{Pd} 3 \mathrm{~d}$. The enhancement of electrocatalytic properties of $\mathrm{Pd}_{10} \mathrm{Au}_{90} / \mathrm{Vulcan}$ was attributed to a strong electronic interaction between $\mathrm{Pd}$ and $\mathrm{Au}$, as evidenced by the modification of the electronic properties of $\mathrm{Pd}$ (possible charge transfer between different chemical elements). For better interaction on gold-based catalysts enabling good performances towards glucose oxidation, either at.\%Pd or at.\%Pt is expected to be slightly higher than $\mathrm{Au}$ at the surface.
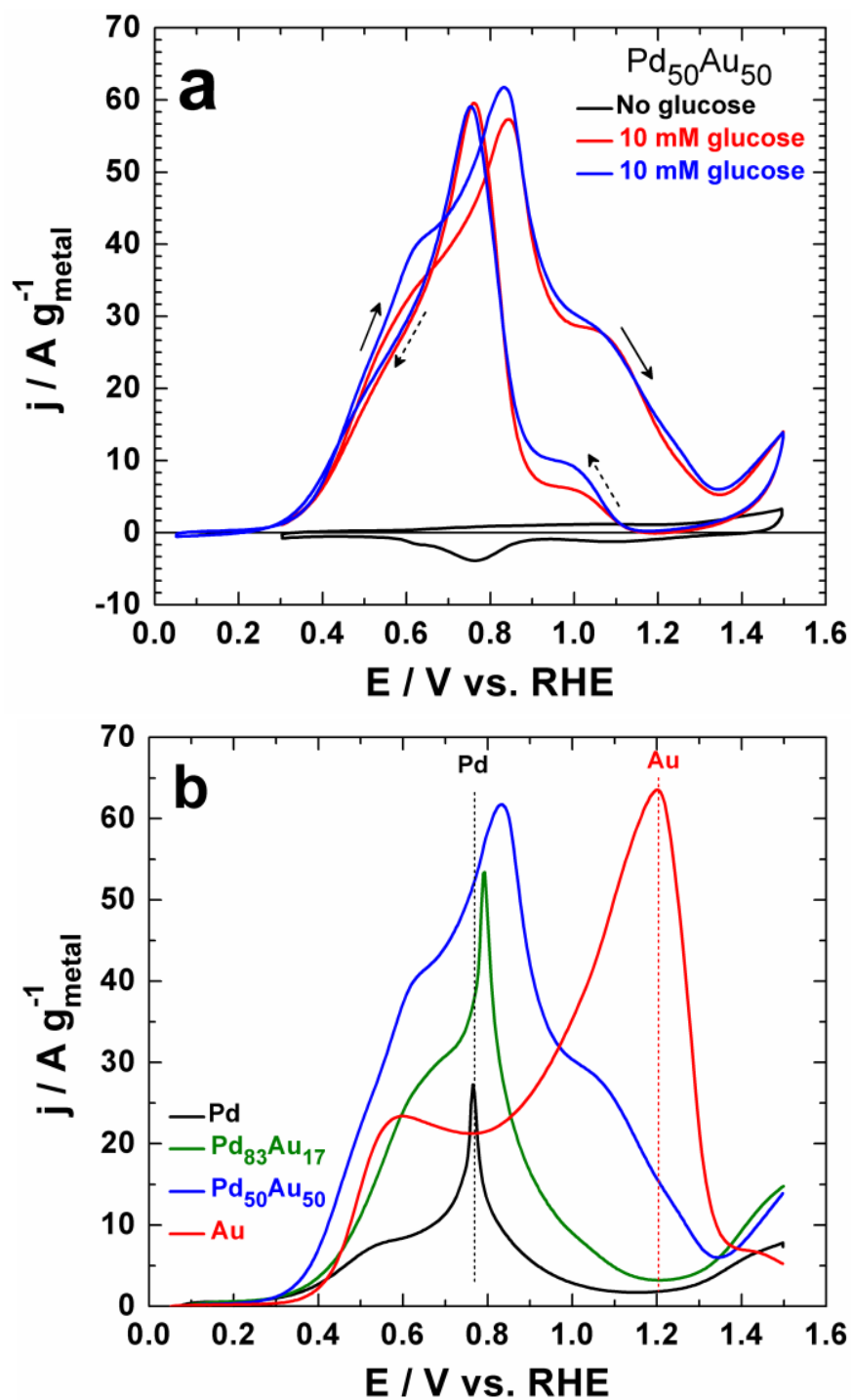

Fig. 4 Electrocatalytic performances of $\mathrm{Pd}_{\mathrm{x}} \mathrm{Au}_{\mathrm{y}}$ electrodes formed by laserablated NPs recorded in $0.1 \mathrm{M} \mathrm{NaOH}$ at $20 \mathrm{mV} \mathrm{s}^{-1}$ and $20^{\circ} \mathrm{C}$ in the presence of $10 \mathrm{mM}$ glucose. (a) $\mathrm{CVs}$ of $\mathrm{Pd}_{50} \mathrm{Au}_{50}$ electrodes in the absence (black) and presence of glucose by starting at either $0.3 \mathrm{~V}$ vs. RHE (red) or $0.05 \mathrm{~V}$ vs. RHE (blue). (b) Comparative glucose electrooxidation polarization curves.

\subsection{Electrocatalytic activities towards glucose electrooxidation}

Fig. 4a shows voltammograms of the $\mathrm{Pd}_{50} \mathrm{Au}_{50}$ catalysts in $0.1 \mathrm{M}$ $\mathrm{NaOH}$ solution containing $10 \mathrm{mM}$ glucose. As shown in the figure, the presence of glucose enables to quench the hydrogen adsorption/absorption phenomenon on Pd, which confirms and underpins the conclusion that glucose impedes the adsorption/absorption of hydrogen in Pd networks. It is worth noting that Al-Odail and co-workers observed that the increase of the $\mathrm{Au}$ content in $\mathrm{Pd}$-based materials decreases both hydrogen absorption and hydrogen evolution. ${ }^{42}$ Here, hydrogen absorption in the PdAu alloys is suppressed monotonically as $\mathrm{Au}$ 
content is increased, with no hydrides $\mathrm{PdH}_{\mathrm{x}}$ formed above ca. 70 at.\% Au. Based on the analysis of polarization curves for different electrode materials (Fig. 4b), we believe that the lifting of any significant current in the hydrogen region between 0.05 $0.3 \mathrm{~V}$ vs. RHE can be mostly attributed to the presence of glucose molecules. Here, by profiting from Au content and the presence of glucose, we were able to suppress efficiently kinetics of this phenomenon for $\mathrm{Pd}_{50} \mathrm{Au}_{50}$ electrode material. Consequently, electrooxidation polarization curves for glucose can be recorded by starting at $0.05 \mathrm{~V}$ vs. RHE without any concern of $\mathrm{Pd}$ structure modification. However, our data indicate that the lower potential limit notably affects the peak current density resulted in the glucose oxidation during the forward scan, while the backward peak remains quite insensitive (Fig. 4a). We attribute this behavior to increased glucose adsorption efficiency at lower potentials, typically for $E$ $<0.3 \mathrm{~V}$ vs. RHE. Indeed, during the positive scan of the electrode potential, high current densities for $\mathrm{E}>0.5 \mathrm{~V}$ vs. RHE depend on the number of glucose molecules that are initially adsorbed at lower potentials. As a result, more molecules can be adsorbed if the process is started at $0.05 \mathrm{~V}$ vs. RHE instead of $0.3 \mathrm{~V}$ vs. RHE. As an evidence, red curve in Fig. 4a does not start exactly at zero current, which means that glucose electrooxidation could start earlier than $0.3 \mathrm{~V}$ vs. RHE.

The initiation of oxidation at minimal overpotential and kinetics at low potentials are key parameters in electrocatalysis of organics. In our case, the onset potential is centered at ca. $0.27 \mathrm{~V}$ vs. RHE, which is very low promising a much-improved operation of fuel cells. In addition, our tests showed that bimetallic PdAu nanoalloys can offer very sharp current increase once the reaction started. Here, the bimetallic $\mathrm{Pd}_{50} \mathrm{Au}_{50}$ shows especially fast enhancement at the kinetics region, i.e. for $E \approx 0.27-0.40 \mathrm{~V}$ vs. RHE. As shown in Fig. $4 b$, at $0.4 \mathrm{~V}$ vs. RHE, $\mathrm{j}=2.7,3.5,7.2$ and $2.2 \mathrm{Ag}^{-1}$ for $\mathrm{Pd}, \mathrm{Pd}_{83} \mathrm{Au}_{17}, \mathrm{Pd}_{50} \mathrm{Au}_{50}$ and $\mathrm{Au}$ respectively. In other words, $\mathrm{Pd}_{50} \mathrm{Au}_{50}$ displays an enhancement factor of 2.7-, 2.1- and 3.3-fold compared with $\mathrm{Pd}, \mathrm{Pd}_{83} \mathrm{Au}_{17}$ and $\mathrm{Au}$ respectively. This excellent kinetics at low potentials is confirmed by better current densities at relatively high potentials. Between 0.6 and $0.8 \mathrm{~V}$ vs. RHE, the region of interest in electrochemical systems (for lower energy demand), the association of $\mathrm{Au}$ and $\mathrm{Pd}$ yields 2- to 3-fold enhancement factors. During the positive going sweep rate, the main oxidation peak centered at $0.8 \mathrm{~V}$ vs. RHE follows a shoulder at ca. $0.6 \mathrm{~V}$. With 50 at.\% Au content, another shoulder can be observed at around $1.1 \mathrm{~V}$ vs. RHE undoubtedly at the surface of $\mathrm{Au}(\mathrm{OH})_{x}$ species, which plays crucial role in glucose electrooxidation. ${ }^{21}$ The main oxidation peak is situated between those of monometallics (ca. 0.8 and $1.2 \mathrm{~V}$ vs. RHE, for Pd and $\mathrm{Au}$ respectively). This behavior evidences the formation of alloy phase on which the oxidation takes place. For comparison, current densities obtained herein at $0.8 \mathrm{~V}$ vs. RHE are at least 2fold higher than those found under the same electrochemical conditions on the $\mathrm{Au}_{70} \mathrm{Pt}_{30} / \mathrm{C}$ catalyst prepared from a soft chemical method. ${ }^{43}$ It is critically important that $\mathrm{Pd}_{50} \mathrm{Au}_{50}$ nanoalloys demonstrate similar activity during the second glucose oxidation step as pure Au nanoparticles. Indeed, as shown in Fig. $4 \mathrm{~b}$, the mass activity of $\mathrm{Pd}_{50} \mathrm{Au}_{50}$ nanoalloys was about $60 \mathrm{~A} \mathrm{mg}^{-1}$, which is comparable with the relevant parameter for pure Au nanoparticles $\left(65 \mathrm{~A} \mathrm{mg}^{-1}\right)$. It means that the improvement of kinetics at low potentials due to the presence of $\mathrm{Pd}$ did not cause any aggravation of electrode performance during the second "glucose oxidation" step, evidencing a synergetic effect of two metals in the system.

Notice that we already explored bare laser-synthesized $\mathrm{Au}$ NPs in similar glucose oxidation tasks. ${ }^{21}$ Profiting from the cleanness of the bare surface, small nanoparticle sizes, and the presence of some preferential crystallographic facets enhancing the catalytic response, we recorded one order of magnitude better activity in glucose oxidation compared to various chemically synthesized Au NPs, including Au NPs stabilized by $C T A B$ and ones prepared by citrate method (the case of bare $A u$ NPs is illustrated by red curve of Fig. 4b). Although the electrocatalytic activity toward glucose oxidation was really impressive, the absence of good affinity of the gold surface with hydrogen did not make possible efficient glucose adsorption leading to excessively high onset potentials and slow kinetics at low potentials. As follows from newly-presented results, such a problem can be solved by the addition of Pd in NPs composition, which looks very easy using laser-ablative methods. On the other hand, the recorded parameters for laser-synthesize $\mathrm{Pd}_{50} \mathrm{Au}_{50}$ nanoalloys, including a low onset potential $(<0.27 \mathrm{~V}$ vs. RHE) and kinetics at lower potentials, accompanied by an impressive activity in the entire potential window, outperform all reported data for alternative bimetallic nanomaterials. ${ }^{43-47}$ Fig. S2 of the Supplementary information shows a comparison of electrocatalytic performances of $\mathrm{Pd}_{50} \mathrm{Au}_{50}$ electrodes formed by laser-ablated NPs and NPs prepared by Bromide Anion Exchange based method recorded in $0.1 \mathrm{M} \mathrm{NaOH}$ at $20 \mathrm{mV} \mathrm{s}^{-1}$ and $20^{\circ} \mathrm{C}$ in the presence of $10 \mathrm{mM}$ glucose. One can see that for laser-synthesized NPs the oxidation of glucose takes place at much lower potentials (with high current density), which confirms that "bare" (surfactant free) NPs can indeed enhance the kinetic of glucose oxidation at low potentials. As a result, laser-based $\mathrm{Pd}_{50} \mathrm{Au}_{50}$ catalyst exhibited high current densities from 0.3 to $0.7 \mathrm{~V}$ vs. RHE. Such an improvement can be explained by synergistic impacts of two metals in the alloy phase and uncontaminated, ligand-free surface of $\mathrm{Pd}_{50} \mathrm{Au}_{50}$ nanoalloy. Currently, the improvement of $\mathrm{Pd}$ catalytic properties when alloyed with other metals $(\mathrm{Au}, \mathrm{Ag}, \mathrm{Ni} . .$.$) has$ been widely studied and attributed to bifunctional mechanisms and/or electronic effects ${ }^{6,48-50}$ According to the d-band theory, when metals such as $\mathrm{Au}$ or $\mathrm{Ag}$ is added into the structure of $\mathrm{Pd}$, the $\mathrm{d}$-band of $\mathrm{Pd}$ can be shifted up. ${ }^{49}, 50$ As a result, more hydroxyls may be adsorbed at the catalyst surface leading to the appearance of additional active sites. In bifunctional mechanism, the addition of $\mathrm{Au}$ to $\mathrm{Pd}$ provides a significant amount of metal-OH species at lower potentials to facilitate the removal/oxidation of co-adsorbed intermediates.

Recent reports of Kokoh et $\mathrm{al}^{5}$ suggested that the performance of glucose fuel cells is mostly limited by mass transport phenomena. The principle of mass transport, also referred as a diffusion-limiting process, consists of bringing the reacting species close enough to the surface of the catalyst and removing the species formed at the surface into the bulk of the 
solution. Thus, it is highly important to clarify the regime of glucose electrooxidation reaction on laser-synthesized $\mathrm{PdAu}$ nanoalloys. To this end, we consider the kinetics study of glucose electrooxidation by changing various parameters such as the scan rate, temperature, etc. The first investigated parameter was potential sweeping rate. Typical positive scanning glucose electrooxidation curves at various potential sweep rates are reported in Fig. S3a for $\mathrm{Pd}_{50} \mathrm{Au}_{50}$. One can see that the peak current density of glucose electrooxidation increases and slightly shifts toward high potentials while the scan rate is increased. As follows from the Randles-Sevcik's equation, the peak current density for a mass transfer process should be proportional to the square root of the sweep rate ${ }^{51}$ :

$$
\mathrm{j}_{\mathrm{P}}=0.443 \mathrm{nFC}_{\text {glu cose }} \sqrt{\frac{\mathrm{nFD}}{\mathrm{RT}}} \times \sqrt{\mathrm{v}}
$$

where $n$ is the number of electrons, $v$ is the scan rate, $F$ is Faraday's constant, $R$ is the universal gas constant, $T$ is absolute temperature, and $D$ is a diffusion coefficient of reactive species.

As expected for a mass transfer controlled process (Equation (2)), the plot of peak current $j_{P}$ versus the square root of scan rate yields a straight line (Fig. S3b). Furthermore, the potential of the peak position shifts while the scan rate is changed. This suggests that the electrocatalytic oxidation of glucose on these laser-synthesized nanocatalysts is an irreversible diffusion controlled process. We then investigated the effect of temperature from 3 to $40{ }^{\circ} \mathrm{C}$ in order to assess precisely the magnitude of this phenomenon. It is worth mentioning that beyond $45{ }^{\circ} \mathrm{C}$, bulk solutions turn from colorless to yellow-brown, as it was observed in previous reports ${ }^{21,52}$. As shown by chromatography analysis, such a change of color was due to the appearance of degradation products at high temperatures, including gluconates resulting from the $\mathrm{HO}^{-}$nucleophile attack of glucose (having an aldehyde group). Our experiments were performed using most active electrocatalyst $\mathrm{Pd}_{50} \mathrm{Au}_{50}$. This diffusion regime can be characterized by the assessment of electrochemical activation energy $\left(E_{a}\right)$, which is related to minimal necessary energy to initiate an electrocatalytic reaction. In the diffusion control regime, the activation energy value is typically low $(<50 \mathrm{~kJ}$ $\mathrm{mol}^{-1}$ ). In contrast, the regime of adsorption-control mainly involves glucose molecules adsorbed the electrode surface and is characterized by high activation energies (>50 $\left.\mathrm{kJ} \mathrm{mol}^{-1}\right)$. The kinetic theory of Arrhenius enables to obtain $E_{a}$ experimentally. The electrochemical formulation of Arrhenius' law is given by Eq. (3). ${ }^{53} 54$ In this case, $E_{a}$ can be determined by Eq. (4) using parameters from Eq. (3).

$$
\mathrm{j}=\mathrm{A} \exp \left[-\frac{\Delta \mathrm{H}^{0}-\alpha \mathrm{nFE}}{\mathrm{RT}}\right]=\mathrm{A} \exp \left[-\frac{\mathrm{E}_{\mathrm{a}}}{\mathrm{RT}}\right] \text { (3) }
$$

$$
E_{a}=-2.3 R\left[\frac{\partial \log (j)}{\partial\left(\frac{1}{T}\right)}\right]_{E, c}
$$

where $A$ is a constant, $\Delta H^{0}$ is the activation enthalpy at standard conditions, $R$ is the universal gas constant $\left(8.314 \mathrm{~J} \mathrm{~mol}^{-1} \mathrm{~K}^{-1}\right), F$ is Faraday's constant, $\alpha$ is the transfer coefficient, $n$ is the number of electrons, $T$ is temperature, $E$ is potential and $c$ is concentration of glucose.
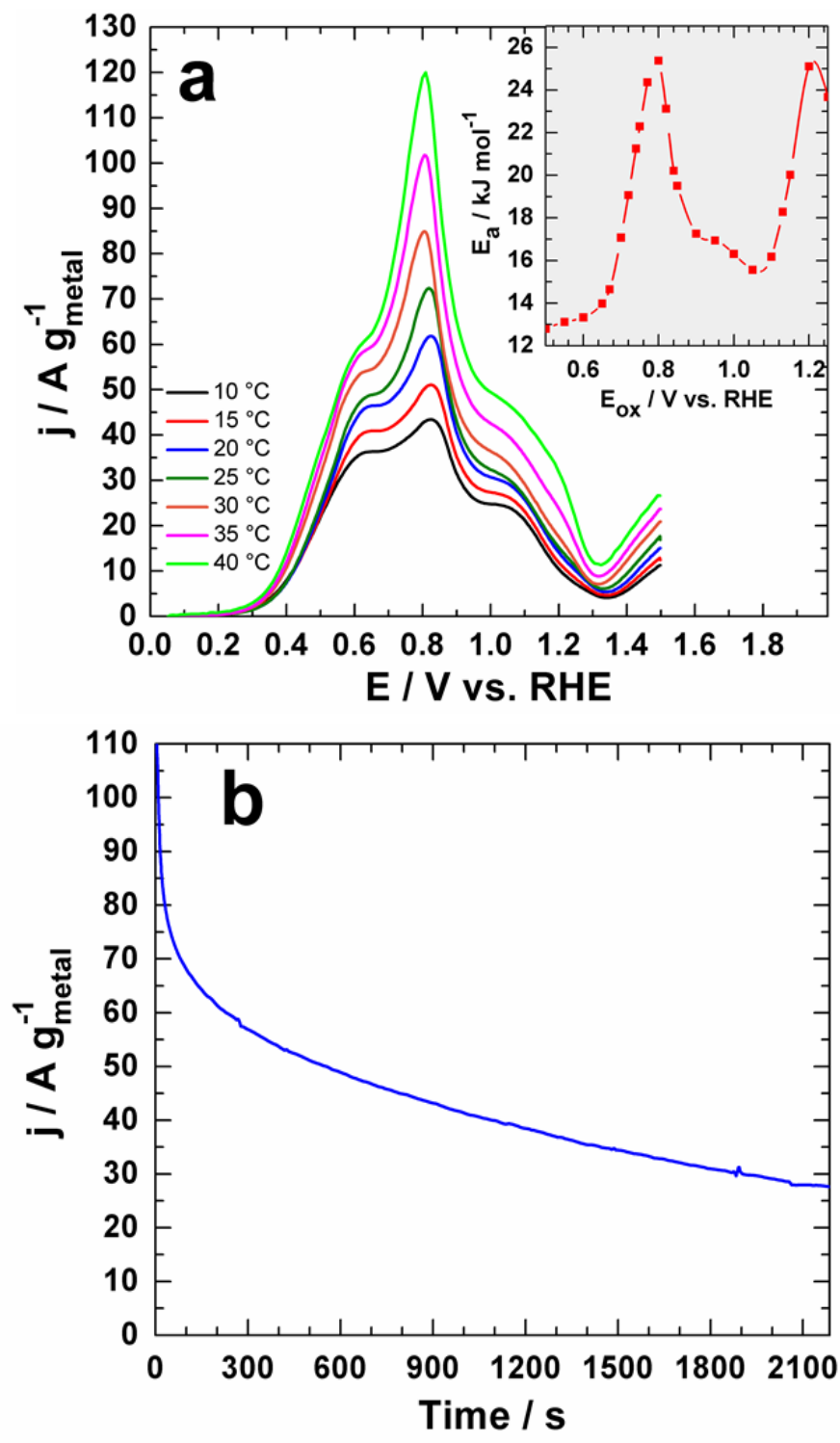

Fig. 5 (a) Glucose electrooxidation polarization curves of $\mathrm{Pd}_{50} \mathrm{Au}_{50}$ electrodes formed by laser-ablated NPs recorded in $0.1 \mathrm{M} \mathrm{NaOH}$ at $20 \mathrm{mV} \mathrm{s}^{-1}$ in the presence of $10 \mathrm{mM}$ glucose and at different temperatures from 10 to $40^{\circ} \mathrm{C}$. The inset represents the plots of the electrochemical activation energy $\left(E_{a}\right)$ evaluated different oxidation potentials $\left(E_{o x}\right)$. (b) $\mathrm{Pd}_{50} \mathrm{Au}_{50}$ electrode stability tested by chronoamperometry recorded at $0.8 \mathrm{~V}$ vs. RHE in $0.1 \mathrm{M} \mathrm{NaOH}$ at $40{ }^{\circ} \mathrm{C}$ and in the presence of $10 \mathrm{mM}$ glucose.

Thus, for electrode potential E, the electrocatalysis has a unique advantage of decreasing the activation enthalpy $\Delta H^{\circ}$ 
(catalyst's contribution at standard conditions) through the electrochemical term " $\alpha n F E$ " (electrical contribution) leading to the so-called electrochemical activation enthalpy $E_{a}=$ $\Delta \mathrm{H}^{0}-\alpha n F E .^{54} \mathrm{Fig}$. 5a displays the polarization curves of glucose electrooxidation obtained using a thermostabilized electrochemical cell. One can see that current densities of oxidation peaks increase while temperature is increased. More importantly, the main peak potential shifts toward lower potentials when temperature is increased up to $40{ }^{\circ} \mathrm{C}$. Such a tendency is opposite to the effect of the sweep rate. In other words, the temperature increase enhances electrochemical kinetics via an exothermic catalytic process $\left(E_{a}>0\right)$. Arrhenius's plots for the $E_{a}$ determination is shown in Fig. S4 and the corresponding values of $E_{a}$, as estimated from Eq. (4), are depicted in inset of Fig. 5 a for different oxidation potentials $\left(E_{o x}\right) . E_{a}$ as function of $E_{o x}$ has a similar shape as potentialcurrent curves recorded at different temperatures. The maximum value of $E_{a}$ is reached at $E_{o x}=0.8 \mathrm{~V} \mathrm{vs}$. RHE, which is also the peak current density. Considering the relationship $E_{a}=$ $\triangle H^{0}-\alpha n F E_{o x}$, one could expect a decrease of $E_{a}$ when $E_{o x}$ increases. It therefore appears that the increase of $E_{o x}$ in the electrical contribution " $\alpha n F E_{o x}$ " is not enough to compensate: (i) possible increase of the activation enthalpy $\Delta H^{\circ}$ that is not obviously constant when the electrode potential $E_{o x}$ increases; and (ii) significant decrease of " $\alpha n$ ". The last hypothesis, if confirmed, would mean that there is almost no electron transfer at peak current. Furthermore, entire values of $E_{a}$ are relatively low and $E_{a}<50 \mathrm{~kJ} \mathrm{~mol}^{-1}$. This suggests that the glucose oxidation reaction kinetics is controlled by diffusion and not reactant adsorption processes, which means that lasersynthesized PdAu nanomaterials can have excellent prospects as anode material in fuel cell applications. It should be noted that the recorded values of $18-22 \mathrm{~kJ} \mathrm{~mol}^{-1}$ were similar to what we earlier observed for pure laser-synthesized Au NPs. ${ }^{21}$ Notice that similar polynomial dependences of $E_{a}$ to Eox has been observed for methanol electrooxidation at Pt bulk, ${ }^{55}$ while similar polynomial trend for glucose electrooxidation at $\mathrm{pH} 7.4$ was recorded ${ }^{56}$ and supported by theoretical calculations of Protsenko and Danilov. ${ }^{57}$

Finally, we evaluated stability of the $\mathrm{Pd}_{50} \mathrm{Au}_{50}$ electrode material in chronoamperometry measurements by following the curve of current density versus time at constant potential of $0.8 \mathrm{~V}$ vs. RHE. It is well-known that monometallic Pt and Pd is promptly deactivated by the reaction intermediates, ${ }^{36}$ while the addition of Au to Pd greatly strengthens the ability of catalysts to withstand the surface poisoning phenomenon. Fig. $5 \mathrm{~b}$ shows an obtained chronoamperogram. The progressive temporal decay of current density decay is a common phenomenon and related to previously reported "mass transport phenomenon" at the electrode-solution interface, which consists in the removal of reaction products and route reactants from catalytic sites. Such a result looks logical, as the experiment was performed without any solution agitation or electrode rotation. The second and more rational reason is a relatively low concentration of glucose that could be exhausted after a few hundreds of seconds. Thus, fast glucose concentration depletion will cause a fast current decay because the amount of the reactive species decreases with time. Anyway, the recorded high current density during the first $1000 \mathrm{~s}$ evidences the robustness of our laser-synthesized $\mathrm{Pd}_{50} \mathrm{Au}_{50}$ nanomaterial, which is capable to withstand perfectly the poisoning phenomena associated with strongly adsorbed species coming from glucose oxidation. Thus, $\mathrm{Pd}_{50} \mathrm{Au}_{50}$ will be an excellent candidate as anode electrode material in glucose-based electrochemical energy conversion devices such as direct alkaline fuel cell, ${ }^{5,44}$ hybrid biofuel cell ${ }^{6,56}$ as well as enzymefree glucose biofuel cell ${ }^{38,58}$ and biosensors construction..$^{59,60}$

\section{Experimental Section}

\subsection{Characterization of laser-synthesized nanomaterials}

Morphology, structure and size of synthesized NP were characterized by the high-resolution transmission electron microscopy (HR-TEM) system (JEOL JEM 3010). Samples were prepared by dropping $5 \mu \mathrm{L}$ of NPs solution onto a carbon-coated TEM copper grid and subsequent drying at ambient conditions. $\zeta$-potential measurements were performed using a Zetasizer ZS instrument (Malvern Instruments, Orsay, France). Extinction spectra of NPs solutions were measured by an UV-VIS spectrophotometer (UV-2600, Shimadzu) using 10-mm optical path length quartz cuvettes. Concentrations of NP solutions were determined by measuring target weight before and after the ablation step.

\subsection{Electrochemical tests}

All electrochemical experiments were carried out using an analogical potentiostat EG\&G PARC Model 362 (Princeton Applied Research) in conventional thermally-stabilized threeelectrode cell (Pyrex glass). All electrochemical experiments were conducted at a controlled temperature. The reference electrode was a homemade reversible hydrogen electrode (RHE), which made possible referring all measured potentials to RHE. To avoid any potential loss due to reactions occurring at the working electrode, RHE was secluded from the solution by a Haber-Luggin capillary tip. A slab of glassy carbon (GC) of 6.48 $\mathrm{cm}^{2}$ geometrical surface area was used as counter electrode. The working electrode consists of a catalytic ink deposited on a $3 \mathrm{~mm}$ diameter GC disc (mounted in Teflon) used as conductive carrier. Prior to each experiment, it was polished with 1 and $0.05 \mu \mathrm{m}$ alumina, followed by several ultrasonic cleanings in ultrapure water. For the ink, no modification was done after the synthesis step. However, in order to get homogeneous and reproducible results, the solution was mixed ultrasonically for few seconds. In preliminary experiments, the working electrode was coated with different volumes in order to find the best conditions. Herein, the optimized condition consists of $6 \mu \mathrm{L}$ of the catalytic ink that are dispensed onto the GC disc, leading to total metal loadings of $14.9,14.8,13.8 \mu_{\text {gmetal }} \mathrm{cm}^{-2}$ for $\mathrm{Pd}$, $\mathrm{Pd}_{83} \mathrm{Au}_{17}$ and $\mathrm{Pd}_{50} \mathrm{Au}_{50}$, respectively. To better access the performances of bimetallic NPs, laser-synthesized AuNPs reported elsewhere ${ }^{21}$ was used as reference material. A supporting $0.1 \mathrm{M} \mathrm{NaOH}$ solution (prepared from $\mathrm{NaOH}$, SigmaAldrich ${ }^{\circledR}, 97 \%$ ) was used a supporting electrode. Electrocatalytic 
performances were evaluated in the presence of $10 \mathrm{mM} \mathrm{D-(+)-}$ glucose (Sigma-Aldrich $\left.{ }^{\circ}, 99.5 \%\right)$, In all experiments, we used ultrapure water as solvent (Milli-Q Millipore) at $20^{\circ} \mathrm{C}$. To avoid interferences from oxygen, solutions were deoxygenated by bubbling nitrogen for thirty minutes before any electrochemical experiment. All the current densities in this work were normalized with the total metal weight.

\section{Conclusions}

The results reported herein demonstrate the successful synthesis of Au-, Pd- and PdAu-based nanoparticles by laser ablation in aqueous solutions and their assessment in glucose oxidation tasks. The nanomaterials demonstrated outstanding activity towards glucose electrooxidation, while $\mathrm{Pd}_{50} \mathrm{Au}_{50} \mathrm{NPs}$ showed the best characteristics to combine high activity and ultrafast kinetics at low potentials.

It is worth noting the bare laser-synthesized nanomaterials are now actively explored in catalytic tasks and have already demonstrated a great potential for a variety of applications due to the absence of ligands or contaminants (for review, see Ref. ${ }^{61}$ ). The interest to these nanomaterials is strongly alimented by recently shown possibilities for cost-reduction and scaling-up of this technology, ${ }^{62}$ which is critically important for catalytic applications. As follows from the presented data and results of our previous study, ${ }^{17}$ laser-synthesized nanomaterials can provide a major breakthrough in electrocatalytic tasks related to the development of direct glucose fuel cells. Results of this work highlight a new rational, convenient and straightforward pathway toward more active nanomaterials design for the electrochemical energy conversion and storage.

\section{Conflicts of interest}

There are no conflicts to declare.

\section{Acknowledgements}

The authors acknowledge contribution of Russian Science Foundation (Project 19-72-30012) for the fabrication of samples of highly calibrated NPs and AMIDEX project (ANR-11-IDEX0001-02) funded by the "Investissements d'Avenir" French Government program, managed by the French National Research Agency (ANR) for fabrication and characterization facilities. S.H., Y.H., K.B.K., and T.W.N. acknowledge the CNRS and the Région Nouvelle Aquitaine for their support. A.V.K., M.S. and P.D. acknowledges support from the MEPhI Academic Excellence Project (Contract No. 02.a03.21.0005).

\section{Notes and references}

1. S. Calabrese Barton, J. Gallaway and P. Atanassov, Chemical Reviews, 2004, 104, 4867-4886.

2. T. Chen, S. C. Barton, G. Binyamin, Z. Gao, Y. Zhang, H.-H. Kim and A. Heller, Journal of the American Chemical Society, 2001, 123, 8630-8631.
F. Bonfatti, Journal of The Electrochemical Society, 1999, 146, 2175

4. Y. Holade, N. Tuleushova, S. Tingry, K. Servat, T. W. Napporn, H. Guesmi, D. Cornu and K. B. Kokoh, Catalysis Science \& Technology, 2020, 10, 3071-3112.

5. Y. Holade, K. Servat, T. W. Napporn, C. Morais, J.-M. Berjeaud and K. B. Kokoh, ChemSusChem, 2016, 9, 252 263.

6. A. Habrioux, K. Servat, S. Tingry and K. B. Kokoh, Electrochemistry Communications, 2009, 11, 111-113.

7. Y. Holade, A. B. Engel, K. Servat, T. W. Napporn, C. Morais, S. Tingry, D. Cornu and K. B. Kokoh, Journal of the Electrochemical Society, 2018, 165, H425-H436.

$8 . \quad$ B. S. Yeo, S. L. Klaus, P. N. Ross, R. A. Mathies and A. T. Bell, ChemPhysChem, 2010, 11, 1854-1857.

9. B. B. Blizanac, M. Arenz, P. N. Ross and N. M. Marković, Journal of the American Chemical Society, 2004, 126, 10130-10141.

10. Q. Xue, H. Huang, J.-Y. Zhu, Y. Zhao, F.-M. Li, P. Chen and Y. Chen, Applied Catalysis B: Environmental, 2020, 278, 119269.

11. Q. Xue, J. Bai, C. Han, P. Chen, J.-X. Jiang and Y. Chen, ACS Catalysis, 2018, 8, 11287-11295.

12. A. Gole and C. J. Murphy, Chemistry of Materials, 2004, 16, 3633-3640.

13. S. E. Lohse and C. J. Murphy, Chemistry of Materials, 2013, 25, 1250-1261.

14. S. Hebié, K. B. Kokoh, K. Servat and T. W. Napporn, Gold Bulletin, 2013, 46, 311-318.

15. S. Hebié, L. Cornu, T. W. Napporn, J. Rousseau and B. K. Kokoh, The Journal of Physical Chemistry C, 2013, 117, 9872-9880.

16. A. V. Kabashin and M. Meunier, Journal of Applied Physics, 2003, 94, 7941-7943.

17. K. Maximova, A. Aristov, M. Sentis and A. V. Kabashin, Nanotechnology, 2015, 26, 065601.

18. A.-L. Bailly, F. Correard, A. Popov, G. Tselikov, F. Chaspoul, R. Appay, A. Al-Kattan, A. V. Kabashin, D. Braguer and M.A. Esteve, Scientific Reports, 2019, 9, 12890.

19. M. Kögler, Y. V. Ryabchikov, S. Uusitalo, A. Popov, A. Popov, G. Tselikov, A.-L. Välimaa, A. Al-Kattan, J. Hiltunen, R. Laitinen, P. Neubauer, I. Meglinski and A. V. Kabashin, Journal of Biophotonics, 2018, 11, e201700225.

20. A. A. Popov, G. Tselikov, N. Dumas, C. Berard, K. Metwally, N. Jones, A. Al-Kattan, B. Larrat, D. Braguer, S. Mensah, A. Da Silva, M.-A. Estève and A. V. Kabashin, Scientific Reports, 2019, 9, 1194

21. S. Hebié, Y. Holade, K. Maximova, M. Sentis, P. Delaporte, K. B. Kokoh, T. W. Napporn and A. V. Kabashin, ACS Catalysis, 2015, 5, 6489-6496.

22. V. Viswanathan, H. A. Hansen, J. Rossmeisl and J. K. Nørskov, The Journal of Physical Chemistry Letters, 2012, 3, 2948-2951.

23. P. Tripodi, N. Armanet, V. Asarisi, A. Avveduto, A. Marmigi, J. D. Vinko and J.-P. Biberian, Physics Letters A, 2009, 373, 3101-3108.

24. M. A. Ryashentseva, Russian Chemical Reviews, 1995, 64 967-983.

25. G. Mazzone, I. Rivalta, N. Russo and E. Sicilia, The Journal of Physical Chemistry C, 2008, 112, 6073-6081. 
26. R. W. J. Scott, C. Sivadinarayana, O. M. Wilson, Z. Yan, D. W. Goodman and R. M. Crooks, Journal of the American Chemical Society, 2005, 127, 1380-1381.

27. L. Shang, F. Zhao and B. Zeng, Electroanalysis, 2013, 25, 453-459.

28. M. Tian, M. Malig, S. Chen and A. Chen, Electrochemistry Communications, 2011, 13, 370-373.

29. M. Mougenot, A. Caillard, M. Simoes, S. Baranton, C. Coutanceau and P. Brault, Applied Catalysis B: Environmental, 2011, 107, 372-379.

30. C. Xu, Z. Tian, Z. Chen and S. P. Jiang, Electrochemistry Communications, 2008, 10, 246-249.

31. A. N. Simonov, P. E. Plyusnin, Y. V. Shubin, R. I. Kvon, S. V. Korenev and V. N. Parmon, Electrochimica Acta, 2012, 76, 344-353.

32. T. Baati, A. Al-Kattan, M.-A. Esteve, L. Njim, Y. Ryabchikov, F. Chaspoul, M. Hammami, M. Sentis, A. V. Kabashin and D. Braguer, Scientific Reports, 2016, 6, 25400.

33. V. M. Petriev, V. K. Tischenko, A. A. Mikhailovskaya, A. A. Popov, G. Tselikov, I. Zelepukin, S. M. Deyev, A. D. Kaprin, S. Ivanov, V. Y. Timoshenko, P. N. Prasad, I. N. Zavestovskaya and A. V. Kabashin, Scientific Reports, 2019, 9, 2017.

34. S. C. Y. Tsen, P. A. Crozier and J. Liu, Ultramicroscopy, 2003, 98, 63-72.

35. Y. Holade, C. Morais, S. Arrii-Clacens, K. Servat, T. W. Napporn and K. B. Kokoh, Electrocatalysis, 2013, 4, 167178.

36.

A. Both Engel, Y. Holade, S. Tingry, A. Cherifi, D. Cornu, K. Servat, T. W. Napporn and K. B. Kokoh, The Journal of Physical Chemistry C, 2015, 119, 16724-16733.

37.

M. Simões, S. Baranton and C. Coutanceau, The Journal of Physical Chemistry C, 2009, 113, 13369-13376.

38. Y. Holade, K. MacVittie, T. Conlon, N. Guz, K. Servat, T. W. Napporn, K. B. Kokoh and E. Katz, Electroanalysis, 2015, 27 276-280.

39. G. F. Alvarez, M. Mamlouk, S. M. Senthil Kumar and K. Scott, Journal of Applied Electrochemistry, 2011, 41, 925937.

40. M. Łukaszewski and A. Czerwiński, Electrochimica Acta, 2003, 48, 2435-2445.

41. D. A. J. Rand and R. Woods, Journal of Electroanalytical Chemistry and Interfacial Electrochemistry, 1972, 36, 57 69.

42. F. A. Al-Odail, A. Anastasopoulos and B. E. Hayden, Physica Chemistry Chemical Physics, 2010, 12, 11398-11406.

43. P. Tonda-Mikiela, T. W. Napporn, C. Morais, K. Servat, A Chen and K. B. Kokoh, Journal of The Electrochemical Society, 2012, 159, H828-H833.

44 D. Basu and S. Basu, International Journal of Hydrogen Energy, 2011, 36, 14923-14929.

45. C. Zhu, S. Guo and S. Dong, Advanced Materials, 2012, 24 2326-2331.

46. L. Yan, A. Brouzgou, Y. Meng, M. Xiao, P. Tsiakaras and S Song, Applied Catalysis B: Environmental, 2014, 150-151, 268-274.

47. J. Dolinska, P. Kannan, J. W. Sobczak and M. Opallo, ChemElectroChem, 2015, 2, 1199-1205.

48. R. P. Doherty, J.-M. Krafft, C. Méthivier, S. Casale, H. Remita, C. Louis and C. Thomas, Journal of Catalysis, 2012, 287, 102-113.
49. S. T. Nguyen, H. M. Law, H. T. Nguyen, N. Kristian, S. Wang, S. H. Chan and X. Wang, Applied Catalysis B: Environmental, 2009, 91, 507-515.

50. Y. Wang, Z. M. Sheng, H. Yang, S. P. Jiang and C. M. Li, International Journal of Hydrogen Energy, 2010, 35, 10087 10093.

51. L. R. F. A. J. Bard, Electrochemical Methods: Fundamentals and Applications, 2nd Edition, John Wiley \& Sons, Inc.,, USA, 2001.

52. L. H. E. Yei, B. Beden and C. Lamy, Journal of Electroanalytical Chemistry and Interfacial Electrochemistry, 1988, 246, 349-362.

53. A. Damjanovic, Journal of Electroanalytical Chemistry, 1993, 355, 57-77.

54. E. Gileadi, Electrodes Kinetics for Chemists, Chemical Engineers, and Materials Scientists, Wiley-VCH, New York, NY, USA, 1993.

55. J. L. Cohen, D. J. Volpe and H. D. Abruña, Physical Chemistry Chemical Physics, 2007, 9, 49-77.

56. Y. Holade, A. Both Engel, S. Tingry, A. Cherifi, D. Cornu, K. Servat, T. W. Napporn and K. B. Kokoh, ChemElectroChem, 2014, 1, 1976-1987.

57. F. I. Danilov and V. S. Protsenko, Russian Journal of Electrochemistry, 2010, 46, 188-195.

Y. Holade, K. MacVittie, T. Conlon, N. Guz, K. Servat, T. W. Napporn, K. B. Kokoh and E. Katz, Electroanalysis, 2014, 26, 2445-2457.

59. J. H. Yuan, K. Wang and X. H. Xia, Advanced Functional Materials, 2005, 15, 803-809.

60. Y.-Y. Song, D. Zhang, W. Gao and X.-H. Xia, Chemistry - A European Journal, 2005, 11, 2177-2182.

61. S. Reichenberger, G. Marzun, M. Muhler and S. Barcikowski, ChemCatChem, 2019, 11, 4489-4518.

R. Streubel, S. Barcikowski and B. Gökce, Opt. Lett., 2016, 41, 1486-1489. 